\title{
\#Supportlocal: how online food delivery services leveraged the COVID-19 pandemic to promote food and beverages on Instagram
}

\author{
Si Si Jia ${ }^{1, *}$, Rebecca Raeside ${ }^{1}$ (1) Julie Redfern ${ }^{1,2}$, Alice A Gibson ${ }^{3}$, Anna Singleton ${ }^{1}$ and \\ Stephanie R Partridge ${ }^{1,4}$ \\ 'Engagement and Co-design Research Hub, School of Health Sciences, Faculty of Medicine and Health, The University \\ of Sydney, Sydney 2145, Australia: ${ }^{2}$ The George Institute for Global Health, The University of New South Wales, \\ Camperdown, Australia: ${ }^{3}$ Menzies Centre for Health Policy and Economics, Sydney School of Public Health, Faculty of \\ Medicine and Health, The University of Sydney, Sydney, Australia: ${ }^{4}$ Prevention Research Collaboration, Sydney \\ School of Public Health, The University of Sydney, Sydney, Australia
}

Submitted 3 March 2021: Final revision received 9 June 2021: Accepted 17 June 2021: First published online 25 June 2021

\begin{abstract}
Objective: To explore the promotion of discretionary foods/beverages and marketing strategies employed by the top three online food delivery services' (OFDS) Instagram accounts in three countries before and during the coronavirus disease 2019 (COVID-19) pandemic.

Design: Publicly available data were extracted for the top three OFDS Instagram accounts for Australia, United Kingdom (UK) and the United States of America (USA) from March to May 2019 and 2020. Food/beverage items from posts were classified as 'discretionary' or from the five food groups (FFG) according to the Australian Dietary Guidelines. Marketing strategies were coded using an existing framework. Posts referring to COVID-19 were coded under four marketing strategies: (i) appropriating frontline workers; (ii) combatting the pandemic; (iii) selling social distancing; and (iv) accelerating digitalisation.

Results: From 581 posts, 618 food/beverage items were shown, of which $69 \%$ (427/618) were classified as discretionary. In 2019, the most used marketing strategies were product imagery (unbranded) (137/195, $70 \%)$, links (111/195, $57 \%$ ) and sponsorships/partnerships (58/195, 30\%). In 2020, the most used were links (252/386, 68\%), product imagery (unbranded) (179/386, 49\%) and branding elements (175/386, $45 \%$ ). The most common COVID-19 marketing strategy was combatting the pandemic $(76 / 123,62 \%)$ followed by selling social distancing $(53 / 123$, $43 \%)$, appropriating frontline workers $(34 / 123,28 \%)$ and accelerating digitalisation (32/123, 26\%).

Conclusions: Following the COVID-19 pandemic, OFDS adapted their marketing, creating content with the theme of 'combatting the pandemic'. Due to the growing number of discretionary foods/beverages promoted on Instagram, this highlights the need for policy action to counter the potential influence social media platforms have on dietary behaviours.
\end{abstract}

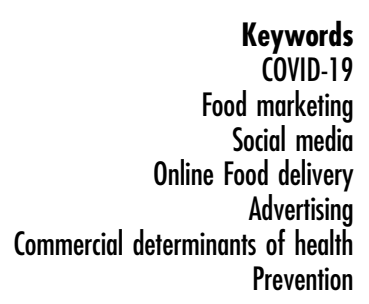

Escalating rates of obesity are a global health concern negatively influencing healthcare systems and economies ${ }^{(1)}$. Over the last four decades, overweight and obesity rates around the world have increased dramatically in children and adolescents aged 5-19 from $4 \%$ in 1975 to over $18 \%$ in $2016^{(2)}$. Poor diet during childhood and adolescence can

Si Si Jia and Rebecca Raeside have equal contributions. lead to excessive weight gain, which in turn increases the risk for chronic diseases such as musculoskeletal disorders, poor mental health, type 2 diabetes and CVD later in life ${ }^{(3)}$. Food and beverage marketing is a powerful environmental factor contributing to poor dietary behaviours and intake. Significant detrimental effects on children's eating behaviours have been demonstrated ${ }^{(4)}$, whether it is through traditional broadcast marketing ${ }^{(5)}$ or product packaging of 
high-saturated fat, high-salt or high-sugar 'junk' foods/ beverages ${ }^{(6)}$. A systematic review of 71 studies revealed that children and adolescents experience enhanced attitudes, preferences and increased consumption of the foods that were marketed to them ${ }^{(7)}$ The review highlighted the need for further attention to be paid to the rise of "contemporary and sophisticated marketing techniques' utilised by new online platforms.

Young people are spending more time engaging in online activities. In the United States of America (USA), over 95\% of youth aged 13-17 years own a smartphone and over $90 \%$ of adolescents report using the Internet multiple times $/ \mathrm{d}^{(8)}$. In the United Kingdom (UK), children aged 12-15 spend nearly $17 \mathrm{~h} /$ week on their mobile phones ${ }^{(9)}$ and in Australia, 14-28-year olds report spending $21 \%$ of their online/digital entertainment time consuming social media ${ }^{(10)}$. In response to the digital age, food and beverage marketing has shifted to alternate avenues such as social networking platforms. To engage with their followers, companies are using display and video advertising, direct consumer-brand interactions on social media accounts and peer-to-peer marketing to create and promote content ${ }^{(11)}$. Digital marketers use strategies that appeal to emotion and entertainment to maximise peer engagement and elicit responses from young people ${ }^{(12)}$. Brands frequently employ the use of humour - which is the most liked advertising tactic by children ${ }^{(13)}$ and has proven effective in maximising engagement on Facebook ${ }^{(14)}$. As such, the effects of marketing on social media on children and young people are concerning. A recent study conducted by Baldwin et al., showed that young people who had a higher online engagement with food brands and content, through digital platforms such as YouTube, were more likely to consume unhealthy foods and drinks ${ }^{(15)}$. A UK study revealed children who viewed images of unhealthy snacks on social media from 'influencers' had increased consumption of these foods compared to children who viewed images of healthy items or non-food items from influencers ${ }^{(16)}$. Furthermore, Rummo et al., found that popular food and sugary drink brands such as Coca Cola ${ }^{\circledR}$, McDonald's ${ }^{\circledR}$ and Pizza Hut ${ }^{\circledR}$ maintain millions of adolescent followers on social media ${ }^{(17)}$. This highlights the wide reach of food marketing on digital platforms where young people are susceptible to the tactics employed by these companies ${ }^{(18)}$.

Easy access to junk foods and beverages enabled by the current food environment adds further complexity to the issue of overweight and obesity amongst adolescents and those emerging into adulthood. Online food delivery services (OFDS) such as UberEats, Doordash and Menulog allow customers to select menu items on their screens and freelance couriers then deliver the chosen items from the kitchen to doorstep ${ }^{(19)}$. A cross-sectional study conducted by Partridge et al., has revealed over $88 \%$ of the most popular menu items on a leading OFDS are energy-dense nutrient-poor foods ${ }^{(20)}$. Similarly, Poelman et al. found that 'burgers', 'pizza' and 'Italian' were in the top ten of most advertised meals on the OFD app and/or website in three international cities ${ }^{(21)}$.

Such platforms are likely affecting the way younger generations purchase foods and beverages. A global consumer survey in 2019 reported $48.4 \%$ of online food delivery users are aged between 18 and 34 years ${ }^{(22)}$. Over $25 \%$ of young people (15-34 years) in Australia and New Zealand report using online food delivery services ${ }^{(23)}$. In Australia, by 16 years of age, nearly $80 \%$ have a debit $\operatorname{card}^{(22)}$ in their name. This is similarly observed in the USA and UK with debit card ownership at $80 \%{ }^{(24)}$ and $91 \%{ }^{(25)}$ respectively, in people aged over 15 . This is critical considering the ease of digital payment options and tools offered on the apps of OFDS, which amplify young people's accessibility to 'junk foods'. A survey in China found over $70 \%$ of young adults have used OFD for at least 2 years and $85 \%$ of them have used OFD more than once per week ${ }^{(25,26)}$.

Furthermore, there are signs indicating OFD usage has soared during the coronavirus disease 2019 (COVID-19) pandemic. In Taiwan, online food shopping services increased by $5.7 \%$ and $4.9 \%$ for each additional confirmed case of COVID-19 ${ }^{(27)}$ China also reported a $766 \%$ increase in business registrations for new OFDS from January to May $2020^{(28)}$. Mexico saw a $60 \%$ increase in visits to OFD websites $^{(29)}$. Globally, OFDS market revenue increased by $27 \%$ Year-Over-Year, reaching $\$ 136.4$ billion in $2020^{(30)}$.

Concerningly, OFD companies are likely capitalising on global events to promote their services. During the 2018 Fédération Internationale de Football Association (FIFA) World Cup Tournament, a Chinese OFDS ('Eleme') spent US $\$ 443$ million on a marketing campaign to offer discounts and coupons to customers watching the tournament ${ }^{(31)}$. Now in the context of the COVID-19 pandemic, there are reports of many food and beverage companies leveraging the pandemic to boost social media marketing of their products and services ${ }^{(25,32)}$.

Instagram is a popular mobile photo and video-sharing social media platform with more than 1 billion monthly active users reported in June 2018. Of Instagram users, $71 \%$ are aged 34 years and younger with the 25-34 years age group having the largest share of the audience, followed by the 18-24 years age group ${ }^{(33)}$. Furthermore, in Australia, there are reports that $51 \%$ of users on an average log in to the app at least 3-5 times/week ${ }^{(34)}$. Previously popular social media platforms, such as Facebook, are declining in popularity with adolescents and young adults ${ }^{(35,36)}$. Given that the highest OFDS users are young people ${ }^{(23,24)}$ who are also the most active Instagram users ${ }^{(10,35)}$, there is an urgent need to investigate how these proliferating OFDS have used Instagram to promote and market their services.

Thus, this study aimed to investigate how the top three OFDS in three countries advertise and promote their service and food outlet partners on their Instagram accounts. The effect of the COVID-19 pandemic on the social media promotion of these OFDS was also explored. 


\section{Methods}

\section{Sample selection}

The publicly available Instagram accounts of the top three OFDS used in Australia (AUS, Oceania region including Australia and New Zealand), the USA (North American region including the USA and Canada) and the UK were selected for content analysis given the similarities in Western-style dietary patterns ${ }^{(37)}$. Furthermore, the USA and UK rank as Western regions with the largest and second largest OFD markets, respectively. For Australia, the OFDS investigated were UberEats, Menulog and Deliveroo. For the UK, these were Just Eat, UberEats and Deliveroo. For the USA, DoorDash, UberEats and GrubHub were the leading three accounts. This selection was dependent on the market share of the OFDS as of 1 September 2020 in each respective region ${ }^{(38)}$.

\section{Data extraction}

From September to November 2020, data extraction was conducted by three authors (RR, SJ, SRP). A two-phase data extraction process was implemented. In phase one, data pertaining to the Instagram account was extracted as of September 2020, which included the number of followers, the number of posts since account inception, the account description and whether the account was verified which was indicated by a blue tick next to the account handle. In phase two, data were extracted from all publicly available posts that were uploaded on the selected accounts between 1 March and 31 May 2019, prior to the COVID-19 pandemic, and 1 March and 31 May 2020, corresponding to the first wave of the COVID-19 pandemic in the select regions ${ }^{(39)}$. The date a post is published appears under the comments section of that post. Using the website version of Instagram, the following data were obtained from each included account: post type (photo or video), number of likes, number of comments, number of views (for videos), the caption (written description or explanation about the photo or video) and hashtag(s) (word or phrase preceded by a hash sign to identify digital content on a specific topic).

\section{Content coding protocol}

A three-phase coding protocol was developed for this study. In the first phase, the nutrition quality of featured foods/beverages and food outlets were coded. According to the Australian Dietary Guidelines, discretionary foods are defined as 'energy-dense' foods and drinks not necessary to provide the nutrients that the body needs. Many are high in saturated fats, sugars, salt or alcohol ${ }^{(40)}$. Alternately, 'nutrient-dense' foods are from the five food groups (FFG): (i) vegetables and legumes; (ii) fruit; (iii) grains and cereals; (iv) lean meats and poultry and alternatives; and (v) dairy and alternatives ${ }^{(40)}$. The content analysis examined the number of food and/or beverage items presented in the post, the number of discretionary items compared to FFG items and the use of food/ beverage emojis (small digital image or icon used to express an idea or emotion $\left.{ }^{(41)}\right)$ in the caption. Posts were coded according to the type of food outlet mentioned in the photo or caption, for example, independent food outlet (i.e., culturebased restaurants such as Thai or Italian restaurants or local take away outlets such as pizza, kebab shops) or franchise fast food outlets/chains (e.g., McDonalds ${ }^{\circledR}$, Domino's Pizza ${ }^{\circledR}$ ).

In phase two, existing marketing coding frameworks were applied from former published studies, where the full list of marketing strategies is reported ${ }^{(41-43)}$. Briefly, these coding guidelines were created by researchers who also examined social media marketing strategies used for junk food promotion - with the first study performed on Facebook $^{(42)}$ and the second on Instagram ${ }^{(43)}$. Posts could be coded into more than one category if multiple marketing strategies were present. Posts were also coded according to whether they were: (i) informational; (ii) original content from the OFDS brand; and (iii) whether health claims were made. Please see Table 1 for the definitions of marketing strategies used to code the posts.

In phase three, a coding protocol was developed for COVID-19-related posts in 2020. This was adapted from the NCD Alliance report which highlighted how food and beverage companies adapted their marketing and promotion of products to reference the pandemic ${ }^{(32)}$. Posts were coded as relating to COVID-19 if there was either explicit content (e.g., OFD brands asked for charity donations to support restaurants affected by COVID-19) or implicit content (e.g., OFD brands offered 'contact-free delivery'). Posts were coded using four main themes. These were: (i) appropriating frontline workers; (ii) 'combatting' the pandemic via promotions; (iii) selling social distancing; and (iv) accelerating digitalisation. Posts could be coded into more than one category. Supplemental Table S1 presents the definitions used ${ }^{(32)}$.

\section{Coding procedure}

The three-member coding team (RR, SJ, SRP) trained together by implementing the three-phase coding framework. The database of posts was equally distributed by region and coded according to the established protocol. Initially, a subsample (20\%) of posts from each researcher was re-coded by the other researchers to check for consistency in coding. Since there were few resulting discrepancies, each researcher independently coded the remaining posts for their designated region. Any discrepancies were discussed until consensus within the team. Two of the three researchers are university-qualified dietitians (SJ, SRP) and reviewed all nutrition-related coding. The data were entered and coded into a purpose-built database using Microsoft Excel (Version 16.46, Microsoft).

\section{Data analysis}

Descriptive statistics were derived including for each individual account, the mean number and range of posts and 
Table 1 Definitions of marketing strategies used to code posts, reproduced from former research ${ }^{(41-42)}$

\begin{tabular}{|c|c|}
\hline Marketing strategy & Definition \\
\hline $\begin{array}{l}\text { Corporate social responsibility } \\
\text { Celebrities }\end{array}$ & $\begin{array}{l}\text { Statement of charitable work, ethical or sustainable initiatives or standpoints undertaken by brand } \\
\text { Individuals with high profile in entertainment or media, excluding athletes }\end{array}$ \\
\hline Sportspeople & $\begin{array}{l}\text { Individuals who show athletic ability and/or sporting achievements, including extreme and motor- } \\
\text { sports }\end{array}$ \\
\hline Children's characters & Notable third-party cartoons or characters from films, books, TV, and the Internet \\
\hline Branded characters & Characters developed by the brand themselves \\
\hline Special price promotion & Reduced price advertisements including discounts, two for one deals or limited time offers \\
\hline Vouchers & Offers only accessible to those who like the account, including print off and/or electronic codes \\
\hline Competitions & Contests that require participant entry and include minimum requirements such as liking a post \\
\hline Engagement & Posts that prompt conversation or interaction \\
\hline Sponsorships/partnerships & Events that the brand supports or brands/service partners - excluding charitable organisations \\
\hline $\begin{array}{l}\text { Videos/graphics interchange format } \\
\text { (GIFs)/boomerangs }\end{array}$ & Moving images \\
\hline Links & Links to additional content, external pages \\
\hline Branding elements & Distinct colours, logos, fonts, slogans or trademarks \\
\hline Product imagery (unbranded) & Pictures of the products sold or their ingredients, with no other branding elements or labels \\
\hline $\begin{array}{l}\text { Image with no clear marketing } \\
\text { strategy }\end{array}$ & Image not associated with any other marketing strategy \\
\hline
\end{tabular}

mean number and range of likes or views and comments. Continuous variables were described as frequencies and percentages. The top three marketing strategies utilised by each OFD brand were determined by a ranking of the number of times a specific technique was used. Percentage distributions were also obtained for COVID-19-related posts and discretionary food-related posts. Ethical approval was not obtained for this study as it included the collation and analysis of publicly available data.

\section{Results}

\section{Instagram account characteristics}

The nine Instagram accounts from the three regions had a collective global following of 933061 accounts (Table 2). Differences were observed within regions and between regions. The USA accounts had the highest mean number of followers, followed by the UK and AUS accounts. The USA UberEats ${ }^{\circledR}$ account had the most followers (50.8\% of total, $n 473$ 777) and the AUS Menulog ${ }^{\circledR}$ account had the least ( $0.9 \%$ of total, $n$ 8154). In September 2020, the 9 accounts had collectively posted a total of 5861 posts since their inception. In 2019, during the study period (1 March-31 May 2019), there were a total of 195 posts representing $3.3 \%$ of the total posts. In comparison, in 2020, during the study period (1 March-31 May 2020), there were a total of 386 posts representing $6.9 \%$ of the total posts. Videos were also posted more frequently in 2020, with 99 videos posted across the 9 accounts, $v$. 18 videos posted in the study period in 2019. Overall, the number of likes and comments per post and views per video across most accounts were low in comparison to the total number of followers $(<1 \%)$, except for the AUS UberEats ${ }^{\circledR}$ account in 2019 which had the highest mean likes and comments.

\section{Content analysis}

Nutritional quality of featured foods and food outlets In 2019, a total of 398 food and beverage items were identified from the 195 posts (Table 3 ). Of the food and beverage items featured, 232 (58.3\%) were discretionary, $144(36 \cdot 1 \%)$ were from the FFGs and $23(5 \cdot 8 \%)$ were unknown. Eighty-two per cent of posts featured at least one food item, and $63 \%$ of those posts displayed more than $50 \%$ discretionary food items (see online Supplemental Table S2). The highest percentage of discretionary foods advertised in 2019 was by GrubHub ${ }^{\circledR}$ (76.0\%). In 2020, a total of 618 food and beverage items featured across the 386 posts (Table 4). Of all the food and beverage items featured, 427 (69.1\%) were discretionary foods and 187 $(30 \cdot 3 \%)$ were from the FFGs. Fifty-eight per cent of posts featured at least one food item, and $69 \%$ of those posts displayed more than $50 \%$ discretionary food items, an increase from 2019 (see online Supplemental Table S2). However, the nutritional quality of featured food and beverages varied between accounts. Three accounts had over $90 \%$ of featured food and beverage items classified as discretionary (AUS Deliveroo ${ }^{\circledR}$, AUS Menulog ${ }^{\circledR}$ and USA UberEats $\left.{ }^{\circledR}\right)$. Across all regions, most food emojis used represented discretionary foods $(72.7 \%$ in AUS; $53.1 \%$ in the USA and $55.5 \%$ in the UK). Links or promotions related to franchise restaurants or fast-food outlets were less frequent than links or promotions related to independent food outlets across all regions. More links or promotions related to independent food outlets were observed in the 2020 study period compared to the 2019 study period. UK accounts had links or promotions related to 87 franchise restaurants or fast-food outlets over both study periods compared to 15 in AUS and 2 in the USA. Similarly, UK accounts had the most links or promotions related to 104 independent food outlets, which changed from 27 in 2019 to 77 in 2020. 


\begin{tabular}{|c|c|c|c|c|c|c|c|c|c|c|c|c|c|c|c|c|c|c|c|c|}
\hline Table 2 Onli & ee food & delivery se & ervices' Ins & stagram & accour & int cha & cteristics & & to May ? & 2019 an & d 2020 & by year & & & & 2019 & & & & \\
\hline $\begin{array}{l}\text { Account name } \\
\text { (Instagram han- } \\
\text { dle) }\end{array}$ & Region & $\begin{array}{c}\text { Followers } \\
(n, \\
\text { September } \\
2020)\end{array}$ & $\begin{array}{l}\text { CovID-19 } \\
\text { in account } \\
\text { description }\end{array}$ & Verified & $\begin{array}{l}\text { Posts } \\
\text { during } \\
\text { study } \\
\text { period }\end{array}$ & $\begin{array}{l}\text { Avg. } \\
\text { likes } \\
\text { per } \\
\text { post }\end{array}$ & Range & $\begin{array}{l}\text { Avg. com- } \\
\text { ments per } \\
\text { post }\end{array}$ & Range & $\begin{array}{l}\text { Videos } \\
\text { with } \\
\text { views } \\
\text { data } \\
\end{array}$ & $\begin{array}{c}\text { Avg. } \\
\text { views } \\
\text { per } \\
\text { video } \\
\end{array}$ & Range & $\begin{array}{l}\text { Posts } \\
\text { during } \\
\text { study } \\
\text { period }\end{array}$ & $\begin{array}{l}\text { Avg. } \\
\text { likes } \\
\text { per } \\
\text { post } \\
\end{array}$ & Range & $\begin{array}{c}\text { Avg. com- } \\
\text { ments } \\
\text { per post }\end{array}$ & Range & $\begin{array}{c}\text { Videos } \\
\text { with } \\
\text { views } \\
\text { data } \\
\end{array}$ & $\begin{array}{l}\text { Avg. } \\
\text { views } \\
\text { per } \\
\text { video } \\
\end{array}$ & Range \\
\hline $\begin{array}{l}\text { Uber Eats } \\
\text { (@ubereat- }\end{array}$ & AUS & 51300 & Yes & Yes & 16 & 172 & $73-385$ & 10 & $1-45$ & 6 & 1249 & 925-1821 & 10 & 45530 & 18 100-204 000 & 143 & $60-253$ & $\mathrm{~N} / \mathrm{A}$ & $\mathrm{N} / \mathrm{A}$ & \\
\hline $\begin{array}{l}\text { S_aus) } \\
\text { Deliveroo } \\
\text { (@ deliver- }\end{array}$ & AUS & 20300 & Yes & Yes & 19 & 218 & $70-817$ & 7 & $1-26$ & 7 & 1051 & 633-1524 & 25 & 100 & 53-247 & 6 & $1-51$ & N/A & N/A & \\
\hline $\begin{array}{l}\text { oo_au) } \\
\text { Menulog }\end{array}$ & AUS & 8154 & No & No & 32 & 83 & $42-116$ & 4 & $1-14$ & 20 & 629 & 4-1476 & 9 & 69 & 59-99 & 4 & $0-13$ & 3 & 1339 & $828-1816$ \\
\hline Grubhub & USA & 95664 & No & Yes & 45 & 329 & $157-561$ & 39 & 11-308 & 11 & 2781 & $1768-4696$ & 37 & 303 & $179-555$ & 17 & $4-35$ & N/A & N/A & \\
\hline $\begin{array}{l}\text { (@grabhub) } \\
\text { DoorDash } \\
\text { (@ doordash) }\end{array}$ & USA & 135779 & No & Yes & 18 & 488 & $302-1356$ & 39 & $6-140$ & 4 & 27311 & $8545-59600$ & 33 & 456 & 261-1017 & 99 & 12-1224 & 1 & $\begin{array}{r}3768 \\
\text { (N- } \\
\text { R) }\end{array}$ & \\
\hline Uber Eats & USA & 473777 & Yes & Yes & 41 & 1315 & $640-3845$ & 147 & $55-417$ & 6 & 13386 & $7246-21000$ & N/A & N/A & & N/A & & N/A & $\mathrm{N} / \mathrm{A}$ & \\
\hline $\begin{array}{l}\text { (@ubereats) } \\
\text { Just Eat (@jus- }\end{array}$ & UK & 41215 & No & Yes & 33 & 179 & 54-395 & 21 & $0-260$ & 19 & 3233 & $602-22400$ & 12 & 102 & 64-175 & 12 & $1-43$ & N/A & N/A & \\
\hline $\begin{array}{l}\text { teatuk) } \\
\text { Uber Eats } \\
\text { (@ubereat- }\end{array}$ & UK & 26358 & Yes & Yes & 10 & 232 & $88-601$ & 94 & 23-299 & 2 & 3264 & $1891-4637$ & N/A & N/A & & N/A & & N/A & N/A & \\
\hline $\begin{array}{l}\text { siuk) } \\
\text { Deliveroo } \\
\text { (@deliveroo) }\end{array}$ & uK & 80514 & No & Yes & 172 & 208 & 71-1032 & 9 & $0-89$ & 24 & 2424 & 809-11 074 & 69 & 191 & $90-1332$ & 9 & $1-42$ & 14 & 1349 & 1-2152 \\
\hline
\end{tabular}


Table 3 Content analysis of discretionary $v$. five food groups items (FFG) across Instagram posts in 2019

\begin{tabular}{|c|c|c|c|c|c|c|c|c|c|c|}
\hline \multirow[b]{2}{*}{$\begin{array}{l}\text { Account name (Instagram } \\
\text { handle) }\end{array}$} & \multirow[b]{2}{*}{ Region } & \multicolumn{9}{|c|}{2019} \\
\hline & & $\begin{array}{l}\text { Total number of food } \\
\text { items, } n\end{array}$ & $\begin{array}{l}\text { Discretionary } \\
\text { foods, } n\end{array}$ & $\begin{array}{c}\mathrm{FFG}, \\
n\end{array}$ & $\begin{array}{l}\text { Unknown, } \\
n\end{array}$ & $\begin{array}{l}\text { Percentage of } \\
\text { discretionary } \\
\text { foods }\end{array}$ & $\begin{array}{l}\text { Food } \\
\text { emojis }\end{array}$ & $\begin{array}{l}\text { Junk food } \\
\text { emojis }\end{array}$ & $\begin{array}{l}\text { Linked to fast food/ } \\
\text { franchise }\end{array}$ & $\begin{array}{l}\text { Linked to } \\
\text { independent } \\
\text { outlet }\end{array}$ \\
\hline Uber Eats (@ubereats_aus) & AUS & 43 & 29 & 9 & 5 & $67.4 \%$ & 9 & 8 & 1 & 2 \\
\hline Deliveroo (@deliveroo_au) & AUS & 59 & 31 & 10 & 18 & $52.5 \%$ & 59 & 31 & 0 & 18 \\
\hline Menulog (@ menulog) & AUS & 19 & 14 & 3 & 0 & $73 \cdot 7 \%$ & 4 & 4 & 5 & 0 \\
\hline Grubhub (@grubhub) & USA & 50 & 38 & 12 & 0 & $76.0 \%$ & 0 & 0 & 0 & 0 \\
\hline DoorDash (@doordash) & USA & 47 & 19 & 28 & 0 & $40.4 \%$ & 9 & 4 & 0 & 5 \\
\hline Uber Eats (@ubereats) & USA & $\mathrm{N} / \mathrm{A}$ & $\mathrm{N} / \mathrm{A}$ & $\mathrm{N} / \mathrm{A}$ & $\mathrm{N} / \mathrm{A}$ & N/A & $\mathrm{N} / \mathrm{A}$ & $\mathrm{N} / \mathrm{A}$ & $\mathrm{N} / \mathrm{A}$ & $\mathrm{N} / \mathrm{A}$ \\
\hline Just Eat (@justeatuk) & UK & 26 & 3 & 23 & 0 & $11.5 \%$ & 0 & 0 & 0 & 0 \\
\hline Uber Eats (@ubereats_uk) & UK & $\mathrm{N} / \mathrm{A}$ & $\mathrm{N} / \mathrm{A}$ & $\mathrm{N} / \mathrm{A}$ & $\mathrm{N} / \mathrm{A}$ & $\mathrm{N} / \mathrm{A}$ & $\mathrm{N} / \mathrm{A}$ & $\mathrm{N} / \mathrm{A}$ & $\mathrm{N} / \mathrm{A}$ & $\mathrm{N} / \mathrm{A}$ \\
\hline Deliveroo (@ deliveroo) & UK & 154 & 98 & 59 & 0 & $59.7 \%$ & 35 & 19 & 21 & 27 \\
\hline Total & & 398 & 232 & 144 & 23 & $58.3 \%$ & 116 & 66 & 27 & 52 \\
\hline
\end{tabular}

Table 4 Content analysis of discretionary $v$. five food groups items (FFG) across Instagram posts in 2020

2020

\begin{tabular}{|c|c|c|c|c|c|c|c|c|c|c|}
\hline \multirow[b]{2}{*}{$\begin{array}{l}\text { Account name (Instagram } \\
\text { handle) }\end{array}$} & \multirow[b]{2}{*}{ Region } & \\
\hline & & $\begin{array}{l}\text { Total number of food } \\
\text { items, } n\end{array}$ & $\begin{array}{l}\text { Discretionary } \\
\text { foods, } n\end{array}$ & $\begin{array}{c}\mathrm{FFG}, \\
n\end{array}$ & $\begin{array}{c}\text { Unknown, } \\
n\end{array}$ & $\begin{array}{l}\text { Percentage of } \\
\text { discretionary } \\
\text { foods }\end{array}$ & $\begin{array}{l}\text { Food } \\
\text { Emojis }\end{array}$ & $\begin{array}{l}\text { Junk food } \\
\text { Emojis }\end{array}$ & $\begin{array}{l}\text { Linked to fast food/ } \\
\text { franchise }\end{array}$ & $\begin{array}{l}\text { Linked to } \\
\text { independent } \\
\text { outlet }\end{array}$ \\
\hline Uber Eats (@ubereats_aus) & AUS & 21 & 11 & 9 & 1 & $52.4 \%$ & 11 & 6 & 0 & 13 \\
\hline Deliveroo (@deliveroo_au) & AUS & 45 & 43 & 2 & 0 & $95.6 \%$ & 0 & 0 & 3 & 8 \\
\hline Menulog (@menulog) & AUS & 55 & 50 & 3 & 2 & $90.9 \%$ & 18 & 13 & 6 & 1 \\
\hline Grubhub (@grubhub) & USA & 51 & 38 & 13 & 0 & $74.5 \%$ & 8 & 7 & 0 & 36 \\
\hline DoorDash (@doordash) & USA & 30 & 16 & 14 & 0 & $53 \cdot 3 \%$ & 3 & 0 & 0 & 1 \\
\hline Uber Eats (@ubereats) & USA & 46 & 44 & 2 & 0 & $95.7 \%$ & 12 & 6 & 0 & 0 \\
\hline Just Eat (@justeatuk) & UK & 15 & 12 & 2 & 1 & $86.7 \%$ & 3 & 3 & 6 & 10 \\
\hline Uber Eats (@ubereats_uk) & UK & 4 & 2 & 2 & 0 & $50.0 \%$ & 0 & 0 & 5 & 1 \\
\hline Deliveroo (@deliveroo) & UK & 351 & 211 & 140 & 0 & $60.1 \%$ & 72 & 39 & 55 & 66 \\
\hline Total & & 618 & 427 & 187 & 4 & $69.1 \%$ & 127 & 74 & 75 & 136 \\
\hline
\end{tabular}


Table 5 Content analysis of COVID-19 marketing strategies from Instagram posts in 2020

\begin{tabular}{|c|c|c|c|c|c|c|c|c|}
\hline Account name & Region & $\begin{array}{l}\text { COVID-19- } \\
\text { related } \\
\text { posts during } \\
\text { study }\end{array}$ & $\begin{array}{l}\text { Food } \\
\text { items }\end{array}$ & Discretionary & $\begin{array}{l}\text { Appropriating } \\
\text { frontline } \\
\text { workers }\end{array}$ & $\begin{array}{l}\text { Combatting } \\
\text { the pan- } \\
\text { demic }\end{array}$ & $\begin{array}{c}\text { Selling } \\
\text { social } \\
\text { distancing }\end{array}$ & $\begin{array}{l}\text { Accelerating } \\
\text { digitalisation }\end{array}$ \\
\hline Uber Eats (@ubereats_aus) & AUS & 2 & 0 & 0 & 1 & 2 & 2 & 2 \\
\hline Deliveroo (@ deliveroo_au) & AUS & 14 & 39 & 38 & 0 & 12 & 14 & 5 \\
\hline Menulog (@menulog) & AUS & 8 & 19 & 19 & 1 & 3 & 6 & 7 \\
\hline Grubhub (@grubhub) & USA & 15 & 51 & 38 & 0 & 15 & 10 & 0 \\
\hline DoorDash (@doordash) & USA & 6 & 30 & 16 & 6 & 5 & 0 & 1 \\
\hline Uber Eats (@ubereats) & USA & 20 & 46 & 44 & 3 & 16 & 4 & 4 \\
\hline Just Eat (@justeatuk) & UK & 21 & 11 & 10 & 15 & 13 & 5 & 1 \\
\hline Uber Eats (@ubereats_uk) & UK & 2 & 0 & 0 & 1 & 2 & 0 & 0 \\
\hline Deliveroo (@deliveroo) & UK & 35 & 24 & 24 & 7 & 8 & 12 & 12 \\
\hline Total & & 123 & 220 & 189 & 34 & 76 & 53 & 32 \\
\hline
\end{tabular}

\section{Marketing strategies}

In 2019, each brand used multiple marketing strategies, ranging from a total of 5 to 11 (see online Supplemental Table S3). The most used marketing strategies were product imagery (unbranded), followed by links and sponsorships or partnerships. The informational posts in 2019, varied from $77.8 \%$ on the AUS Menulog ${ }^{\circledR}$ to $100 \%$ on AUS UberEats ${ }^{\circledR}$ and Deliveroo ${ }^{\circledR}$, USA GrubHub ${ }^{\circledR}$ and UK Just Eat ${ }^{\circledR}$. Majority of posts were original content created by the OFD brand, with the exception of the UK Deliveroo ${ }^{\circledR}$ account with only $36 \cdot 2 \%$ (25/69) original content. The frequency of health claims was low with only 3 out of $195(1.5 \%)$ unique posts making a health claim.

Similarly, data from 2020 found each brand used between 5 and 13 marketing strategies (see online Supplemental Table S4). The most used marketing strategies were branding elements, followed by links and then sponsorships or partnerships. The number of informational posts was highly variable between accounts, ranging from $9 \cdot 1 \%$ on the UK Just Eat ${ }^{\circledR}$ account to $100 \%$ on the AUS Deliveroo ${ }^{\circledR}$ and USA DoorDash ${ }^{\circledR}$ accounts. The majority of posts were original content created by the brand, except for the USA Grubhub ${ }^{\circledR}$ account, which only had 33.3 \% (15/ 45) of posts with original content. OFDS mainly used 'regrammed' images, where a post is reposted content from another Instagram user (customer) and the user's account with the original post is tagged in the post. Lastly, only $1 /$ $386(0.3 \%)$ unique posts in 2020 made a health claim. There were no noticeable differences in marketing strategies across the different regions in both 2019 and 2020.

\section{COVID-19 marketing strategies}

Of the 386 total posts during the first wave of the COVID-19 pandemic in 2020, 123 (31.9\%) was referred to COVID-19 (Table 5). However, this varied greatly between accounts, with each company taking a different approach. For instance, US OFD brand DoorDash only explicitly mentioned 'COVID-19' once in all in their posts during the data extraction period for 2020. Rather, they showcased their partnering restaurants and used hashtags such as '\#OpenforDelivery' or '\#ThankADasher'. On the other hand, major OFD brand UberEats, frequently created posts about 'staying in' or 'quaranentertainment' in a more lighthearted manner. The lowest percentage was the AUS UberEats ${ }^{\circledR}$ account with $12.5 \%$ (2/16) of posts referring to COVID-19, and the highest was the AUS Deliveroo ${ }^{\circledR}$ account with $73.7 \%(14 / 19)$ of posts referring to COVID-19 (see online Supplemental Table S5).

The most common marketing strategy identified for COVID-19 was combatting the pandemic ( $n 76,61.8 \%$ ) followed by selling social distancing ( $n$ 53, 43.1\%), appropriating frontline workers ( $n 34,27 \cdot 6 \%)$ and lastly accelerating digitalisation ( $n 32,26 \cdot 0 \%$ ). Of the 220 food items featured in COVID-19-related posts, most food items were classified as discretionary (98.3\% AUS; $77.2 \%$ USA and $97.1 \% \mathrm{UK})$.

\section{Case studies - COVID-19 marketing strategies}

Four case studies are presented below for each of the COVID-19 marketing strategies to demonstrate the coding of posts (see online Supplemental Table S6).

'Combatting the pandemic via marketing/promotions'. The most used strategy by OFD companies was combatting the pandemic via marketing or promotions. Due to social distancing restrictions, many outlets were not able to allow customers to dine-in but offered take-away food and beverages for pick up or delivery instead. Supplemental Table S6 demonstrates how OFDS created content to encourage customers to stay at home and get food delivered to support local businesses. The USA UberEats account posted Image 1 encouraging customers to 'order in' and promoting a 'Delivery and Takeout Guide' to support local restaurants. Image 2 is from the UK UberEats account who offered free delivery 'to help support independent restaurants', to encourage people to stay home and to reassure their customers that they were 'here for you'.

'Selling social distancing'. Another commonly identified strategy was selling social distancing. The public health measure, which enforces a ' 1.5 metre' physical distance apart, was capitalised on by OFD companies in their Instagram posts during the early months of the pandemic. For instance, food items were shown to measure distance. Image 1 posted on the AUS Menulog ${ }^{\circledR}$ account used fried chicken buckets from KFC to sell social distancing. 
'Appropriating frontline workers'. Furthermore, most OFD companies associated their services with health care and other frontline workers during the pandemic. Image 1 from the UK Just Eat account outlines their support for the National Health Service (NHS) and saved staff $£ 3.3 \mathrm{M}$ by offering free meals. Similarly, the AUS Menulog account offered AUD $\$ 120000$ of vouchers to healthcare workers on International Nurses Day (Image 2), showing customers their corporate social responsibility during the pandemic.

'Accelerating digitalisation'. OFD companies also harnessed the acceleration in digitalisation and increase in virtual interaction. Image 1 from the USA DoorDash account demonstrated this by creating a virtual lunchroom for those who were working from home, with support from various restaurants. Image 2 from the UK Deliveroo account also highlights the increase in virtual interaction, offering the chance to win food credit for those hosting a virtual wedding.

\section{Discussion}

This study investigated and compared advertising and promotion strategies of the top 3 OFDS in 3 international regions from 581 Instagram posts in periods prior to and during the COVID-19 pandemic. OFD accounts across all regions recorded an increase in Instagram posts in 2020, a likely reflection of the emerging popularity of OFDS globally. Branding elements were used more as a marketing strategy in 2020 compared to 2019 , arguably due to amplified brand awareness during the pandemic, which saw an increased demand for OFDS due to government-enforced stay-at-home measures ${ }^{(38)}$. The number of posts increased in 2020 during the pandemic and the proportion of posts featuring discretionary foods/beverages also appeared to have increased from $58.3 \%$ in 2019 to $69.1 \%$ in 2020 , with three OFD accounts featuring discretionary foods/beverages in over $90 \%$ of all food-related posts. In 2020, during the pandemic, one in three posts referenced the pandemic, with 'combatting the pandemic' identified as the most common COVID-19 marketing strategy. Many foods and beverages featured in COVID-19-related posts were discretionary foods, with over $97 \%$ of COVID-19 posts in AUS and UK featuring discretionary foods. Taken together, the findings from this study demonstrate the heightened brand visibility of OFDS globally and their increasing propensity to promote and market unhealthy foods and beverages that are easily accessible through contactless home delivery.

Branding elements, such as OFD logos, colours and slogans were utilised in the top three marketing strategies in 2020, however, were less frequently utilised in 2019. In 2019, the OFDS relied on unbranded product imagery and links to partner food outlets to market their service. Between 2019 and 2020, there were a higher number of users of OFDS worldwide and this was a larger increase compared to previous yearly increases ${ }^{(38)}$. With more users during the 2020 COVID-19 pandemic, OFDS have potentially used the opportunity to build brand exposure and reinforce their branding to new customers. Previous research has demonstrated that constant exposure to branding elements through digital marketing can evoke the consumer to form an ongoing relationship with that brand ${ }^{(11)}$. OFDS are the intermediary company between food outlets and customers, and the results from this study indicate such services are becoming their own unique brands, for example, UberEats is synonymous with its green and black colours and slogans such as 'Tonight I'll be eating...'.

All social media accounts of the nine OFDS across three international regions were found to have primarily used the tactic of 'combatting the pandemic' in Instagram posts during the early months of the pandemic. Commonly used phrases and words such as 'Support Local', 'Grateful', 'Thanks for delivering' or 'Community', appeared frequently in posts published in the study period. These findings emulate the discussion reported by the NCD Alliance, which postulates that companies have leveraged the pandemic to entice their consumers to do their part and show 'civic duty'(32). In the context of OFDS, these brands heavily promoted content intended to make users feel that they could support local restaurants, delivery drivers and other small businesses affected by the lockdowns and stay-athome orders. Similarly, Gerritsen et al., conducted a content analysis of social media posts published by the top twenty food and beverage brands in New Zealand during the COVID-19 pandemic. They found that the most used theme in $36 \%$ of all COVID-19 social media posts had invoked feelings of community support ${ }^{(25)}$. Previous research has also demonstrated that consumers' intentions to use OFDS are associated with their perceived self-image ${ }^{(44)}$. During the COVID-19 pandemic, consumers were experiencing a sense of shared identity and sense of community, which was capitalised on by OFDS. It is likely that multiple analytic tools would have been utilised by OFDS during this time to develop effective marketing strategies, given the rich volume of data that consumers voluntarily disclose to $\operatorname{OFDS}^{(45)}$.

Furthermore, there appeared to be an association between the theme of 'combatting the pandemic' and 'corporate social responsibility'. Corporate social responsibility is a marketing tactic that promotes the company's community involvement, contribution to charities and environmentally friendly efforts ${ }^{(46)}$. In this present study, 'corporate social responsibility' emerged as one of the top three strategies used in 2020 across all OFD brands, which was not the case in 2019. Concerningly, 'corporate social responsibility' appears to be a potent digital marketing strategy, capable of influencing behaviours of young adults. Buchanan and colleagues, explored the impacts of digital marketing on energy drink consumption behaviours of young adults ${ }^{(47)}$. It was demonstrated that young adults were strongly impacted by content that displayed 'corporate social responsibility' and was unaware that this was a marketing tactic.

The results of this study also showed more discretionary menu items being promoted on the Instagram accounts of 
the nine selected OFDS in 2020 compared to 2019 (58.3\%$69.1 \%$, respectively). Findings from this study echo Vassallo and colleagues' content analysis of posts on Instagram that promote junk food. Vassallo et al., revealed that discretionary brands promote their energy-dense nutrient-poor food menu items more than FFG items on social media ${ }^{(43)}$. In a study by Holmberg and colleagues, it was found that $85 \%$ of adolescent users on Instagram shared images containing food items and the majority (67.7\%) of these posts were of discretionary foods that were energy-dense, nutrient-poor ${ }^{(48)}$ and likewise, a recent study in Belgium reported $67 \%$ of food images seen by adolescents on social media were discretionary items such as burgers, pizza, chips ${ }^{(18)}$. Altogether, the findings from former research indicate that not only are adolescents sharing posts with images of junk food, they are also seeing a monumental volume of such posts on their social media feed. OFD platforms are vessels for a wide variety of energy-dense nutrient-poor brands. Thus, the consequences of such heavy promotion of discretionary menu items are amplified in the context of OFDS

The popularity of unhealthy food images on Instagram may be attributed to the greater capacity unhealthy food items have in capturing and maintaining attention. In a visual attention study conducted by Doolan et al., it was revealed that unhealthy food items attract greater interest than healthy and non-food items, measured by increased attentional bias ${ }^{(49)}$. Similarly, former research has shown young people have more engaged responses to unhealthy food advertising posts on digital platforms. This was marked by increased attention, memory, positive assessment of peers and likelihood to share ${ }^{(50)}$. Findings from the present study also unveiled the tendency of OFD brands to use 'product imagery' as a marketing strategy. Unbranded product imagery appeared in the top three marketing strategies for all the investigated OFD platforms. The 'sight' or appearance of food has been suggested to be a high food value with impacts on purchase intention ${ }^{(51)}$ and can result in higher levels of consumption of the food/product ${ }^{(52)}$. Taken together, the imagery of foods is a powerful tool to market poor nutritional quality food and has significant impacts on consumer behaviours. This is critical given the strong body of evidence that condemns the marketing of unhealthy food and its contribution to the escalating overweight and obesity rates $^{(53-56)}$.

\section{Strengths and limitations}

This study adds to the emerging evidence regarding the public health implications of OFDS, specifically the use of social media for the promotion of food and beverages prepared outside of the home. Other studies have also monitored the marketing strategies of unhealthy food and drink companies on social media during the COVID-19 pandemic ${ }^{(25,32)}$. A strength of the methodological approach of the current study was the comparison of two study periods - prior to and during COVID-19 to allow for comparison. However, the study is not without limitations. First, it is recognised that this study only looked at OFDS marketing on one form of social media (Instagram), whereas OFDS companies are promoting their services across other social media platforms as well, including Facebook, Snapchat and TikTok. Social media content is usually replicated and shared across multiple platforms, therefore, it is likely the most relevant content was analysed. However, possible platform-specific content could have been missed. Although Instagram was selected as it is a leading social media platform for adolescents and young people, other social media platforms may capture different audiences within this demographic.

A further limitation of the current study is that only traditional social media marketing was analysed. Traditional media, also termed 'owned media' is where a company posts on its only social media account directly to its followers. User-generated content that tags the OFD companies in the posts or comments were not included in this study. As well, this study did not consider paid advertising, such as utilising advertising services offered by Instagram to promote a post to a target audience ${ }^{(57)}$. Paid advertisements that specifically target consumers by demographic characteristics, geographical location and interests or hobbies are challenging to monitor retrospectively. In addition, new strategies of food and beverage marketing are increasingly popular on Instagram, such as marketing via paid social media 'influencers' ${ }^{(58)}$. Influencers' posts about a food or beverage item are likely to have an impact on their followers' purchasing and consumption behaviours, especially amongst young people ${ }^{(59)}$. Coates et al., demonstrated that in preadolescents, exposure to influencer's messages with brand name unhealthy snacks led them to prefer the promoted branded snack, relative to an alternative brand ${ }^{(60)}$.

When considering the engagement of the followers, there were only a small percentage of followers who were liking and commenting on each post. This is in line with previous research which suggests that very few followers will engage with any one post ${ }^{(61)}$. Therefore, it must be considered how much influence these posts are having on consumer purchasing and consumption behaviours. In addition to this, the number of followers from the previous year cannot be recorded retrospectively and therefore it is difficult to deduce the following that these accounts had in 2019 (pre-pandemic). However, the number of unique posts almost doubled in 2020 compared to 2019 across the nine accounts. This may reflect notable growth in these platforms and how they may have leveraged the COVID-19 pandemic to create more relatable content to appeal to their target market.

\section{Conclusions}

This study highlights an increase in discretionary food and beverages content on Instagram in three international 
regions during the COVID-19 pandemic. It also identified the potential heightened brand awareness of OFDS over the 1-year time period from 2019 to 2020 and showcased how OFDS adapted their marketing to create pandemicspecific content. Policy action may be required to counter the potential negative influences that OFD platforms can have on dietary behaviours.

\section{Acknowledgements}

Acknowledgements: None. Financial support: This work was supported by a National Health and Medical Research Council (NHMRC) of Australia and National Heart Foundation (NHF) Early Career Fellowship awarded to S.R.P. (APP1157438); NHMRC Career Development Fellowship awarded to J.R. (APP1143538); NHMRC Emerging Leader 1 Investigator Grant awarded to A.A.G. (APP1173784); and Australian Government Research Training Program Scholarship and the Westmead Applied Research Centre's Supplementary Postgraduate Research Scholarship in Breast Cancer awarded to A.C.S. Conflict of interest: There are no conflicts of interest. Authorship: All authors formulated the research questions and designed the study. S.S.J., R.R. and S.R.P. carried out the study and analysed the data. All authors contributed to writing of the article and all authors have read and agreed to the published version of the manuscript. Ethics of human subject participation: Ethical approval was not obtained for this study as it included the collation and analysis of data available in the public domain.

\section{Supplementary material}

For supplementary material accompanying this paper visit https://doi.org/10.1017/S1368980021002731

\section{References}

1. Tremmel M, Gerdtham U-G, Nilsson PM et al. (2017) Economic burden of obesity: a systematic literature review. Int J Environ Res Public Health 14, 435.

2. World Health Organization (2020) Obesity and overweight. https://www.who.int/news-room/fact-sheets/detail/obesityand-overweight (accessed January 2021).

3. Lobstein T, Baur L \& Uauy R (2004) Obesity in children and young people: a crisis in public health. Obes Rev 5, Suppl. 1, 4-104.

4. Norman J, Kelly B, McMahon A-T et al. (2018) Sustained impact of energy-dense TV and online food advertising on children's dietary intake: a within-subject, randomised, crossover, counter-balanced trial. Int J Behav Nutr Phys Act 15, 37.

5. Powell LM, Wada R, Khan T et al. (2017) Food and beverage television advertising exposure and youth consumption, body mass index and adiposity outcomes. Can J Econ $\mathbf{5 0}$, 345-364.

6. Robinson TN, Borzekowski DL, Matheson DM et al. (2007) Effects of fast food branding on young children's taste preferences. Arch Pediatr Adolesc Med 161, 792-797.
7. Smith R, Kelly B, Yeatman H et al. (2019) Food marketing influences children's attitudes, preferences and consumption: a systematic critical review. Nutrients $\mathbf{1 1}, 875$.

8. Anderson M \& Jiang J (2018) Teens, social media \& technology. https://www.pewresearch.org/internet/2018/05/31/teenssocial-media-technology-2018 (accessed January 2021).

9. Ofcom (2019) Children and parents media use and attitudes: annex 1. https://www.ofcom.org.uk/_data/assets/pdf_file/ 0027/134892/Children-and-Parents-Media-Use-and-AttitudesAnnex-1.pdf (accessed March 2021).

10. Deloitte (2018) Media Consumer Survey 2018: Australian Media and Digital Entertainment Preferences, 17th ed. https:// www2.deloitte.com/content/dam/Deloitte/au/Documents/ technology-media-telecommunications/deloitte-au-tmt-mediaconsumer-survey-2018-081019.pdf (accessed March 2021).

11. Montgomery KC \& Chester J (2009) Interactive food and beverage marketing: targeting adolescents in the digital age. $J$ Adolesc Health 45, S18-S29.

12. Boyland E \& Tatlow-Golden M (2017) Exposure, power and impact of food marketing on children: evidence supports strong restrictions. Eur J Risk Reg 8, 224-236.

13. Federal Trade Commission (2012) A Review of Food Marketing to Children and Adolescents. https://www.ftc. gov/sites/default/files/documents/reports/review-foodmarketing-children-and-adolescents-follow-report/121221 foodmarketingreport.pdf (accessed March 2021).

14. Lee D, Hosanagar K \& Nair HS (2015) Advertising Content and Consumer Engagement on Social Media: Evidence from Facebook. https://www.gsb.stanford.edu/faculty-research/ working-papers/advertising-content-consumer-engagementsocial-media-evidence (accessed March 2021).

15. Baldwin HJ, Freeman B \& Kelly B (2018) Like and share: associations between social media engagement and dietary choices in children. Public Health Nutr 21, 3210-3215.

16. Coates AE, Hardman CA, Halford JCG et al. (2019) Social media influencer marketing and children's food intake: a randomized trial. Pediatrics 143, e20182554.

17. Rummo PE, Cassidy O, Wells I et al. (2020) Examining the relationship between youth-targeted food marketing expenditures and the demographics of social media followers. Int J Environ Res Public Health 17, 1631.

18. Qutteina Y, Hallez L, Mennes N et al. (2019) What do adolescents see on social media? A diary study of food marketing images on social media. Front Psychol 10, 2637.

19. Statista (2021) Online Food Delivery: Australia. https://www. statista.com/outlook/374/107/online-food-delivery/australia (accessed January 2021).

20. Partridge SR, Gibson AA, Roy R et al. (2020) Junk food on demand: a cross-sectional analysis of the nutritional quality of popular online food delivery outlets in Australia and New Zealand. Nutrients 12, 3107.

21. Poelman MP, Thornton L \& Zenk SN (2020) A cross-sectional comparison of meal delivery options in three international cities. Eur J Clin Nutr 74, 1465-1473.

22. Statista (2020) Online Food Delivery: Worldwide. https:// www.statista.com/outlook/374/100/online-food-delivery/ worldwide\#market-age (accessed June 2020).

23. Roy Morgan Research (2020) Meal delivery services double usage in only 18 months. https://www.roymorgan.com/ findings/8270-food-delivery-services-september-2019202002030451 (accessed June 2020).

24. Warren D, Andalon M \& Gasser C (2019) Growing Up in Australia: The Longitudinal Study of Australian Children (LSAC) Annual Statistical Report 2018. https://growin gupinaustralia.gov.au/research-findings/annual-statisticalreports-2018/shop-or-save-how-teens-manage-their-money (accessed February 2021).

25. Gerritsen S, Sing F \& Lin K (2021) The timing, nature and extent of social media marketing by unhealthy food and 
drinks brands during the COVID-19 pandemic in New Zealand. Front Nutr $\mathbf{8}, 65$.

26. Yin Y \& Hu J (2019) The analysis of the advantages and disadvantages of the online food delivery phenomenon in universities and the research on the countermeasures-based on the empirical study of Jiangpu campus of Nanjing university of technology and its surroundings. Pop Stand 16, 46-48.

27. Chang H-H \& Meyerhoefer CD (2021) COVID-19 and the demand for online food shopping services: empirical evidence from Taiwan. NBER Working Papers 27427, 448-465.

28. Tianyan Check Data Institute (2020) Takeaway drives total catering revenue: data shows that takeaway companies add more than 100,000 more this year. https://www.thepaper. cn/newsDetail_forward_7851139 (accessed April 2021).

29. Statista (2020) Change in visits to online food delivery services during the COVID-19 outbreak in Mexico from February to October 2020. https://www.statista.com/statistics/ 1118615/visits-online-services-mexico/ (accessed April 2021).

30. AJOT (2021) Online food delivery market to hit $\$ 151.5 \mathrm{~B}$ in revenue and $1.6 \mathrm{~B}$ users in 2021 , a $10 \%$ jump in a year. https://ajot.com/news/online-food-delivery-market-to-hit151.5b-in-revenue-and-1.6b-users-in-2021-a-10-jump-in-ayear (accessed April 2021).

31. The Motley Fool (2018) Alibaba's Ele.me Gets $\$ 3$ Billion Campaign to Take on China's Food Delivery Market. https:// www.fool.com/investing/2018/07/29/alibabas-eleme-gets-3billion-campaign-to-take-on.aspx (accessed March 2021).

32. NCD Alliance (2020) Signalling Virtue, Promoting Harm Unhealthy Commodity Industries and COVID-19. https:// ncdalliance.org/resources/signalling-virtue-promoting-harm (accessed January 2021).

33. Statista (2018) Number of monthly active Instagram users from January 2013 to June 2018. https://www.statista.com/ statistics/253577/number-of-monthly-active-instagram-users/\#: :text=In\%20June\%202018\%2C\%20Instagram\%20had,800\% 20million\%20in\%20September\%202017 (accessed January 2021).

34. Statista (2018) Share of Instagram users in Australia as of April 2018, by frequency of use. https://www.statista.com/statistics/ 649099/australia-share-of-instagram-users-by-frequency/ (accessed January 2021)

35. eSafety Commissioner Australian Government (2020) Australian digital teens: time online and activities - infographic. https:// www.esafety.gov.au/about-us/research/digital-lives-aussieteens/australian-digital-teens-time-online-and-activitiesinfographic (accessed February 2021).

36. Pew Research Center (2019) Share of U.S. adults using social media, including Facebook, is mostly unchanged since 2018. https://www.pewresearch.org/fact-tank/2019/04/10/shareof-u-s-adults-using-social-media-including-facebook-is-mostlyunchanged-since-2018/ (accessed January 2021).

37. Azzam A (2020) Is the world converging to a 'Western diet'? Public Health Nutr 24, 309-317.

38. Statista (2021) Online Food Delivery. https://www.statista. com/outlook/dmo/eservices/online-food-delivery/worldwide (accessed February 2021).

39. World Health Organization (2021) Timeline: WHO's COVID19 response. https://www.who.int/emergencies/diseases/ novel-coronavirus-2019/interactive-timeline/\#! (accessed February 2021).

40. National Health and Medical Research Council (2013) Australian dietary guidelines. https://www.nhmrc.gov.au/_files_nhmrc/ file/publications/n55_australian_dietary_guidelines1.pdf (accessed January 2021).

41. Kaye LK, Malone SA \& Wall HJ (2017) Emojis: insights, affordances, and possibilities for psychological science. Trends Cogn Sci 21, 66-68.
42. Freeman B, Kelly B, Baur L et al. (2014) Digital junk: food and beverage marketing on Facebook. Am J Public Health 104, e56-e64.

43. Vassallo AJ, Kelly B, Zhang L et al. (2018) Junk food marketing on Instagram: content analysis. JMIR Public Health Surveill 4, e54.

44. Gunden N, Morosan C \& DeFranco A (2020) Consumers' intentions to use online food delivery systems in the USA. Int J Contemp Hosp Manag 32, 1325-1345.

45. Rightly (2020) What are the top five food apps doing with your data? https://www.rightly.co.uk/blog/what-are-topfive-food-apps-doing-your-data/ (accessed April 2021).

46. Leonard D \& McAdam R (2003) Corporate social responsibility in a total quality management context: opportunities for sustainable growth. Corp Gov 3, 36-45.

47. Buchanan L (2018) The influences of digital marketing of energy drinks on the food-related attitudes and behaviours of young adults in Australia. PhD Thesis, University of Wollongong.

48. Holmberg C, John E, Chaplin J et al. (2016) Adolescents' presentation of food in social media: an explorative study. Appetite 99, 121-129.

49. Doolan KJ, Breslin G, Hanna D et al. (2014) Visual attention to food cues in obesity: an eye-tracking study. Obesity 22, 2501-2507.

50. Murphy G, Corcoran C, Tatlow-Golden M et al. (2020) See, like, share, remember: adolescents' responses to unhealthy-, healthy- and non-food advertising in social media. Int $J$ Environ Res Public Health 17, 2181.

51. Pérez-Villarreal HH, Martínez-Ruiz MP, Izquierdo-Yusta A et al. (2020) Food values, benefits and their influence on attitudes and purchase intention: evidence obtained at fast-food hamburger restaurants. Sustainability $\mathbf{1 2}, 7749$.

52. McCrickerd K \& Forde CG (2016) Sensory influences on food intake control: moving beyond palatability. Obes Rev 17, 18-29.

53. Chandon P \& Wansink B (2012) Does food marketing need to make us fat? A review and solutions. Nutr Rev $\mathbf{7 0}$, 571-593

54. Cairns G, Angus K, Hastings G et al. (2013) Systematic reviews of the evidence on the nature, extent and effects of food marketing to children. A retrospective summary. Appetite 62, 209-215.

55. Clark CR, Doraszelski U \& Draganska M (2009) The effect of advertising on brand awareness and perceived quality: an empirical investigation using panel data. Quant Mark Econ 7, 207-236.

56. Buchanan L, Kelly B, Yeatman H et al. (2018) The effects of digital marketing of unhealthy commodities on young people: a systematic review. Nutrients 10, 148.

57. Stephen AT \& Galak J (2012) The effects of traditional and social earned media on sales: a study of a microlending marketplace. J Mark Res 49, 624-639.

58. Influencer Marketing Hub (2019) Influencer Marketing Benchmark Report: 2019. https://influencermarketinghub. com/IM_Benchmark_Report_2019.pdf (accessed February 2021).

59. Folkvord F, Anschütz DJ, Nederkoorn C et al. (2014) Impulsivity, "advergames," and food intake. Pediatrics 133, 1007-1012.

60. Coates AE, Hardman CA, Halford JCG et al. (2019) The effect of influencer marketing of food and a "protective" advertising disclosure on children's food intake. Pediatr Obes 14, e12540.

61. Kite J, Foley BC, Grunseit AC et al. (2016) Please like me: facebook and public health communication. PLoS One 11, e0162765. 